\title{
Stock collapse and its effect on species interactions: Cod and herring in the Norwegian-Barents Seas system as an example
}

\author{
Joël M. Durant ${ }^{1}$ (D) | Leana Aarvold ${ }^{1}$ | Øystein Langangen ${ }^{2}$ (D)
}

${ }^{1}$ Centre for Ecological and Evolutionary Synthesis (CEES), Department of Biosciences, University of Oslo, Oslo, Norway

${ }^{2}$ Section for Aquatic biology and toxicology (AQUA), Department of Biosciences,

University of Oslo, Oslo, Norway

\section{Correspondence}

Joël M. Durant, Centre for Ecological and Evolutionary Synthesis (CEES), Department of Biosciences, University of Oslo, PO Box 1066 Blindern, NO-0316 Oslo, Norway.

Email: joel.durant@ibv.uio.no

Funding information

Norges Forskningsråd, Grant/Award

Number: 244647, 280467 and 280468

\begin{abstract}
Both the Norwegian Spring Spawning herring (Clupea harengus) and the Northeast Arctic (NEA) cod (Gadus morhua) are examples of strong stock reduction and decline of the associated fisheries due to overfishing followed by a recovery. Cod and herring are both part of the Barents Sea ecosystem, which has experienced major warming events in the early (1920-1940) and late 20th century. While the collapse or near collapse of these stocks seems to be linked to an instability created by overfishing and climate, the difference of population dynamics before and after is not fully understood. In particular, it is unclear how the changes in population dynamics before and after the collapses are associated with biotic interactions. The combination of the availability of unique long-term time series for herring and cod makes it a well-suited study system to investigate the effects of collapse. We examine how species interactions may differently affect the herring and cod population dynamic before and after a collapse. Particularly we explore, using a GAM modeling approach, how herring could affect cod and vice versa. We found that the effect of cod biomass on herring that was generally positive (i.e., covariation) but the effect became negative after the collapse (i.e., predation or competition). Likewise a change occurred for the cod, the juvenile herring biomass that had no effect before the collapse had a negative effect after. Our results indicate that the population collapses may alter the inter-specific interactions and response to abiotic environmental changes. While the stocks are at similar abundance levels before and after the collapses, the system is potentially different in its functioning and may require different management action.
\end{abstract}

KEYWORDS

climate effects, cod, collapse, demographic effects, herring, population dynamics

\section{1 | INTRODUCTION}

At the stock level, the Norwegian Spring Spawning (NSS) herring (Clupea harengus) is a text book example of overexploitation of marine fish populations with a positive outcome. Due to overexploitation, the NSS herring stock collapsed in the 1960s from a biomass of more than 14 million tonnes in 1956 to less than 0.1 million tonnes in 1972 (Toresen \& Østvedt, 2000), but is now counted as one of the largest herring stocks in the world (Engelhard \& Heino, 2004). At the species level, the Atlantic cod (Gadus morhua) is a prime example for the overexploitation of marine fish populations (Sguotti et al., 2019), with the Northern cod collapse in the early 1990s being a major 
example of a stock collapse without a recovery even after the introduction of a fishing moratorium (Bundy et al., 2009; Hutchings \& Rangeley, 2011). On the other hand, the Northeast Arctic (NEA) cod, despite having experienced a major decline in abundance (hereafter referred to as a collapse) in the early 1980s (Hylen, 2002) is currently at an historically high biomass and supports a healthy fishery (about 849,000 tonnes in 2016; ICES, 2017).

Abrupt and unexpected transitions between alternative system states are often the consequence of climate change, overexploitation or a combination of both (Benson \& Trites, 2002; Daskalov, 2002; Hare \& Mantua, 2000). Commercially exploited fish species that experienced population collapse are prominent examples with important socio-economic ramifications (Beisner et al., 2003; Frank et al., 2011; Myers \& Worm, 2003; Steneck \& Wahle, 2013). Studying the population dynamic and the effect of the population structure on the population change of two co-occurring fish in the Norwegian sea-Barents Sea system (Figure 1), Rouyer et al. (2011) concluded that the NSS herring and NEA cod stocks were responding to environmental forcing differently before compared to after the collapses. Studying 11 exploited stocks, Durant and Hjermann (2017) showed that the population growth dependence on reproduction was linked to the stock structure and hence likely the level of fishing (Law, 2000; Ottersen et al., 2006).

While stock collapses seem to be linked to instability created by overfishing in conjunction to climate (Sguotti et al., 2019), the difference of dynamics before and after a major abundance, decline

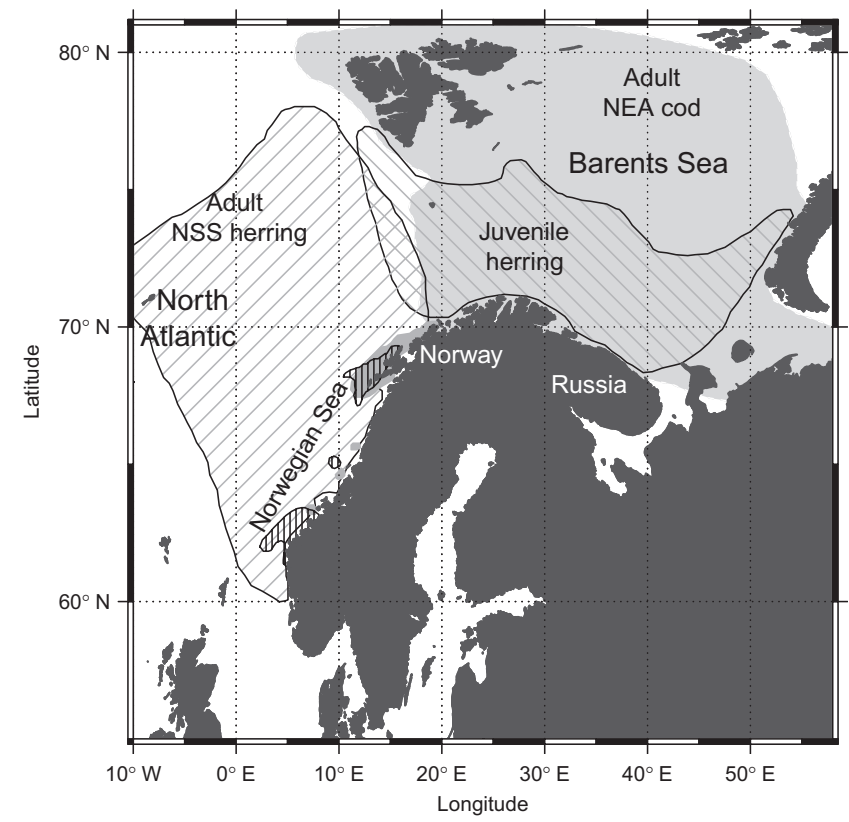

FIGURE 1 General distribution of the Northeast Arctic cod Gadus morhua and the Norwegian spring spawning herring Clupea harengus in the Norwegian Sea-Barents Sea system. The major spawning grounds for herring (vertical dashed lines) and cod (dark grey) are indicated along the coast of Norway. Map based on an Institute of Marine Research in Bergen report from 2016 (Bakketeig et al., 2016) is less well understood. Although Rouyer et al. (2011) previously described the effect of collapse on both NEA cod and NSS herring stocks, they did not consider the interactions between them. Here, we hypothesis that a collapse, in addition to modifying the response to harvesting intensity and climate forcing, will change the trophic interactions. Both NEA cod and NSS herring, for the latter up to 3-4 years of age as the adults living in the North Atlantic, are part of the Barents Sea ecosystem and can interact. For instance, Minto and Worm (2012), investigating the relationships between small pelagic fish and Atlantic cod recruitment throughout the North Atlantic. They found predominantly negative relationships between herring abundance and cod recruitment, suggesting that herring has a consistently negative effect on cod recruitment (albeit not for the Norwegian-Barents Seas system). In the North Sea, Hjermann et al. (2013) show that herring may compete with young cod for food and may in turn be preyed upon by large cod in a reversal of dominance pattern (Fauchald, 2010). In the Barents Sea, Holt et al. showed that cod are feeding on herring using stomach content data (Holt et al., 2019). Here, we hypothesize that the stock collapses may have changed how the abundance of young NSS herring affects the NEA cod dynamic and how the NEA cod abundance is affecting the NSS herring dynamic.

The Barents Sea ecosystem experienced major warming events in the early (1920-1940) and late (1975-ongoing) 20th century (Bengtsson et al., 2004). Sea temperature fluctuations are mainly governed by atmospheric forcing and climate cycles. One such driver in the North Atlantic is the North Atlantic Oscillation index (NAO, Hurrell \& Deser, 2009), which captures complex spatio-temporal variability into a simple metric and integrates larger scale climate processes and their variability (Hallett et al., 2004). It has been documented that the NAO for winter months (wNAO, December-March) can affect different organisms in the Barents Sea such as the NEA cod (Hjermann et al., 2004) and the NSS herring (Tiedemann et al., 2021). Sea temperature affects the fish early life stages in the Barents Sea though survival and growth (Dingsør et al., 2007), distribution (Hidalgo et al., 2012), and recruitment (Ottersen et al., 2013). In the Barents Sea, the Kola transect sea temperature (ST, Bochkov, 1982; Tereschenko, 1996) is representative of the Atlantic water masses in the south-central Barents Sea (Ingvaldsen et al., 2003) and explains the dynamics for NEA cod (Hjermann et al., 2004) and development of both cod and herring (Ottersen \& Loeng, 2000). Kola transect sea temperature correlates positively with strong year-classes of NEA cod (reviewed by Ottersen et al., 2014). Both wNAO and sea temperature have previously been used as environmental drivers to explain population growth in the Barents Sea (Durant \& Hjermann, 2017; Rouyer et al., 2011).

To understand how stock collapse may affect population dynamic, we compared the population dynamic of stocks before and after a collapse. The combination of unique long-term time series for NSS herring and NEA cod in an ecosystem that experienced large fluctuations of temperature and fishing pressure constitutes a wellsuited case study to investigate the effects of collapse. To have a 
common metric directly comparable, we calculated the dominant eigenvalues (de Kroon et al., 1986) of age-structured transition matrices (Brosset et al., 2019; Durant \& Hjermann, 2017; Durant et al., 2008; Rouyer et al., 2011) summarizing the vital rates of the population (survival and reproduction) and representing a proxy for the year to year population changes in one value. This allows us to examine how a collapse could alter the effect of the age structure, the fishing mortality, sea temperature, the North Atlantic oscillation, and/or interacting species on the annual change in the dominant eigenvalue.

\section{2 | MATERIALS AND METHODS}

To understand how stock collapse may affect the population dynamic, we modeled the change of the log-transformed dominant eigenvalue $\lambda_{1}$ of the annual transition matrices in two interacting stocks for the periods before and after a collapse. For each period, we related the temporal variability in each stock $\ln \left(\lambda_{1}\right)$ to demographic variables such as fishing mortality and mean age of the spawning stock, as well as to environmental variables (both regional and large-scale climate indices) and potential interacting species (age 1-3 herring biomass, cod spawning stock (i.e., large cod) biomass; Table 1). The rationale for looking at the effect of environmental variables, which only indirectly affect the realized annual population growth rate, is that these variables may influence several demographic variables simultaneously, including recruitment and age of maturity (Rouyer et al., 2011).

\section{1 | Data}

The data are model-based estimates derived from a form of Virtual Population Analysis (VPAs). These analyses are based on data from commercial catches, calibrated with fisheries' independent survey data and combined with estimates of natural mortality. Table 1 summarizes sources of the data used.

Data for NEA cod (Gadus morhua) were obtained from the longterm VPA performed by Hylen (2002) over the period 1913-1999 and from the International Council for the Exploration of the Sea (ICES) VPA performed over the period 1946-2016 (ICES, 2017).

Data for NSS herring (Clupea harengus) were obtained from the VPA performed by Toresen and Østvedt (2000) over the period 1907-1998 and from the ICES VPA performed over the period 1950-2015 (ICES, 2007, 2015). The consistency of the different abundance sources was confirmed by Rouyer et al. (2011) by comparing the time series of abundance of each age class in the overlapping years (1946-2000 for cod and 1988-1997 for herring).

Since annual values on the proportion of maturity at age was only available from 1950 onward; we extended the ICES matrix of maturity at age for the period 1907-1949 by replicating the year 1950 (using instead average maturity values for the years before the collapse, that is, 1950-1964 see later, did not lead to a significant difference of $\lambda_{1}$ ).

To define the period of collapse, we calculated the $50 \%$ quantile of $\ln \left(\lambda_{1}\right)$ for each time series separately (see below for calculation of $\left.\ln \left(\lambda_{1}\right)\right)$. We then located the year when $\ln \left(\lambda_{1}\right)$ passed the $50 \%$ quantile at the end of the time series for the data covering the period before

TABLE 1 Data source

\begin{tabular}{|c|c|c|c|c|}
\hline Stock & Period $^{a}$ & \multicolumn{2}{|l|}{ Data } & Source \\
\hline NEA cod & 1913-1999 (1921-1973) & \multicolumn{2}{|l|}{$\begin{array}{l}\text { Fishing mortality }\left(F_{5-10}\right) \\
\text { Maturity at age }(\%) \\
\text { Number at age }\left(10^{3}\right) \\
\text { Biomass }\left(10^{5} \mathrm{t}\right)\end{array}$} & $\begin{array}{l}\text { Hylen (2002), Rouyer et al. (2011) } \\
\text { Hylen (2002), Rouyer et al. (2011) } \\
\text { Hylen (2002), Rouyer et al. (2011) } \\
\text { Hylen (2002), Rouyer et al. (2011) }\end{array}$ \\
\hline NEA cod & $1946-2016$ (1981-2013) & $\begin{array}{l}\text { Fishing mortality }\left(F_{5-10}\right) \\
\text { Maturity at age }(\%) \\
\text { Number at age }\left(10^{3}\right) \\
\text { Biomass }\left(10^{3} \mathrm{t}\right)\end{array}$ & $\begin{array}{l}\text { Table } 3.18 \text { p } 160 \\
\text { Table } 3.11 \text { p } 147 \\
\text { Table } 3.16 \text { p } 156 \\
\text { Table } 3.18 \text { p } 160\end{array}$ & $\begin{array}{l}\text { ICES (2017) } \\
\text { ICES (2017) } \\
\text { ICES (2017) } \\
\text { ICES (2017) }\end{array}$ \\
\hline NSS herring & 1907-1998 (1921-1964) & $\begin{array}{l}\text { Fishing mortality }\left(F_{5-12}\right) \\
\text { Maturity at age }(\%) \\
\text { Number at age }\left(10^{6}\right) \\
\text { Biomass }\left(10^{3} \mathrm{t}\right)\end{array}$ & $\begin{array}{l}\text { Table } 7 \text { p } 245 \\
\text { Table } 5 \text { p } 242 \\
\text { Table } 6 \text { p } 243 \\
\text { Table } 8 \text { p } 248 \\
\text { (Total - SSB) }\end{array}$ & $\begin{array}{l}\text { Toresen and } \varnothing \text { stvedt (2000) } \\
\text { Toresen and } \varnothing \text { stvedt (2000) } \\
\text { Toresen and } \varnothing \text { stvedt (2000) } \\
\text { Toresen and } \varnothing \text { stvedt (2000) }\end{array}$ \\
\hline \multirow[t]{4}{*}{ NSS herring } & \multirow[t]{4}{*}{$1950-2015$ (1974-2011) } & Fishing mortality $\left(F_{5-12}\right)$ & $\begin{array}{l}\text { Table } 3.4 .2 \text { p } 66+ \\
\text { Table 7.6.2.3.2 p } 463\end{array}$ & ICES (2017) + ICES (2015) \\
\hline & & Maturity at age (\%) & Table 7.4.5.1 p 451 & ICES, 2015 \\
\hline & & Number at age $\left(10^{9}\right)$ & $\begin{array}{l}\text { Table } 3.4 .1 \text { p } 64+ \\
\text { Table 7.6.2.3.1 p } 462\end{array}$ & ICES (2017) + ICES (2015) \\
\hline & & Biomass $\left(10^{6} \mathrm{t}\right)$ & $\begin{array}{c}\text { Table 7.6.2.3.3 p } 464 \\
\text { (Total - SSB) }\end{array}$ & ICES (2015) \\
\hline
\end{tabular}

Abbreviations: NEA, Northeast Arctic; NSS, Norwegian Spring Spawning; SSB, Spawning Stock Biomass.

${ }^{a}$ Maximum year period covered by the data. The years used for the different GAM analyses are given between parentheses. Virtual population analysis (VPA) data being not reliable in the later years we used a shorter time series than available. 
the collapse and at the beginning of the time series for the data covering the period after the collapse. Using this method, the collapse period for the herring was 1965-1973 and for the cod 1974-1980. We analyzed the data outside the collapse periods: in 1921-1964 and 1974-2011 for the herring and 1921-1973 and 1981-2013 for the cod.

\section{2 | Dependent variable $\ln \left(\lambda_{1}\right)$}

To allow for a direct comparison between the two studied stocks while integrating the maximum information, that is, spawning biomass, recruitment, abundance, and maturity, from the complex agestructured dynamics of NEA cod and NSS herring, we summarized the vital rates (time- and age-specific survival, fecundity, and recruitment success) in an annual transition matrix $A_{t}$ (matrix $A$ at time $t$ ). By definition, the population size in the following year $\left(n_{t+1}\right)$ is the product of the matrix $A_{t}$ and the current year's population size $\left(n_{t}\right)$, where the " $n$ " are vectors representing the number of individuals for each age class. For each year $t$, the transition matrix $A_{t}$ is defined as follows:

$$
A_{t}=\left[\begin{array}{ccccc}
R_{1, t} & R_{2, t} & R_{3, t} & \ldots & R_{\text {amax }, t} \\
S_{1-0, t} & 0 & 0 & \cdots & 0 \\
0 & S_{2-1, t} & 0 & \cdots & 0 \\
\cdots & \cdots & \cdots & \cdots & \cdots \\
0 & 0 & 0 & S_{\text {amax-(amax }-1), t} & 0
\end{array}\right]
$$

with $R_{a, t}$ the contribution of each age-class $a$ to the recruitment at year $t$ and with $S_{a-(a-1), t}$ the survival of age $a-1$ at year $t$ to age $a$ at year $t+1$, computed as the ratio of the abundance of age $a$ at year $t$ and age $a-1$ at year $t-1$. The age index $a$ varies between 1 and $a$ max, the older age-class in the population (respectively $a \max =12$ years and $a \max =14$ years for cod and herring). Note that for both stocks, the last age classes (15+ for herring and $13+$ for cod) were ignored in order not to get an unrealistic survival $S_{a \max -(a \max -1)}>1$. $S$ been directly calculated through abundance estimates, $S_{a-(a-1)}$ can be approximated to $\exp \left(-\left(M_{a-(a-1)}+F_{a-(a-1)}\right)\right)$ with $M$ the natural mortality and $F$ the fishing mortality for age $a$.

$R_{a, t}$ the contribution of each age-class $a$ to the recruitment at year $t$ was defined as follows:

$$
R_{a, t}=\frac{\operatorname{Rec}_{t} \mathrm{MAT}_{a, t-1}}{\sum_{a^{\prime}=1}^{a^{\prime}=a \max } \mathrm{MAT}_{a^{\prime}, t-1} N_{a^{\prime}, t-1}}
$$

where $\operatorname{Rec}_{t}$ is the recruitment at year $t, \mathrm{MAT}_{a, t-1}$ the proportion of mature at age $a$ and time $t-1$ and $N_{a, t-1}$ the abundance for age $a$ at time $t-1$. Note that our model does not take into account the difference of egg productivity between age classes but only the maturity in percent.
We built annual transition matrices $A_{t}$ independently for two sets of data for NEA cod (1913-1999 and 1946-2016) and the two sets for NSS herring (1907-1998 and 1950-2015).

As a convenient way to summarize the year-specific information contained in the transition matrices, we calculated their dominant eigenvalue $\left(\lambda_{1}\right)$. We interpret the dominant eigenvalue as a proxy for population growth for the given year. This interpretation is supported by a positive correlation between the eigenvalue and per capita growth rate (Figure S1). However, we note that the two measures of population growth do not necessary capture the same dynamics as the eigenvalue accounts for the age structure, while the per capita growth is a more aggregated measure. Specifically, we get four time series of $\lambda_{1 \text { t }}$ with the same scale and consequently directly comparable, which for convenience were log-transformed $\lambda_{1}\left(\ln \left(\lambda_{1}\right)\right.$ fluctuating around 0$)$. Since no data on recruitment at age 1 was available for NEA cod, we used as a recruitment proxy the age 3 data with a lag of 3 years and we set the survival between the first and second year and between the second and third year $\left(S_{2-1, t}\right.$ and $S_{3-2, t}$ ) to 1 . It has previously been shown that the choice of this value does not substantially affect the estimate of $\lambda_{1}$ (Rouyer et al., 2011). We tested this assumption by using for the two first years $S_{4-3, t}=\exp \left(-\right.$ Mortality $\left._{4-3, t}\right)$ reported by ICES (Table 3.17 p158 ICES, 2017). The use of this lower and variable survival while affecting the calculated value of $\lambda_{1}$ did not affect the final model. For NSS herring, we used the age 0 recruitment provided by Toresen and Østvedt (2000) and the ICES outputs (Table 1).

\section{3 | Explanatory variables}

As species potentially interacting with the cod, we used the immature herring biomass $\left(B_{\text {herr }}\right.$, annual difference between the total stock biomass and the spawning stock biomass (SSB),

Table 1. We used immature herring since adult herring are absent from the Barents Sea. For the herring models, we used the cod SSB $\left(B_{\text {cod }}\right)$ as potential competitor/predator (Table1).

The mean age in the spawning stock (MA), that was shown to affect population dynamic for both stocks (Durant \& Hjermann, 2017; Rouyer et al., 2011), was calculated as the abundance-weighted average of the ages of mature fish across age classes for both NEA cod and NSS herring:

$$
\mathrm{MA}_{t}=\frac{\sum_{a=a \min }^{a=a \max } a \mathrm{MAT}_{a, t} \mathrm{~N}_{a, t}}{\sum_{a=a \min }^{a=a \max } \mathrm{MAT}_{a, t} \mathrm{~N}_{a, t}}
$$

with amin and amax being, respectively, the age of the youngest and the oldest age group contributing to the abundance of the spawners in year $t, \mathrm{MAT}_{a, t}$ the proportion of mature fish at age $a$ and time $t$, and $N_{e, t}$ the number of fish at age $a$ and time $t$.

The fishing mortality $(F)$ is given for age groups 5-10 $\left(F_{5-10}\right)$ and age groups 5-12 $\left(F_{5-12}\right)$ for cod and herring, respectively (Table 1$)$. $F$ represents the average removal of fish from the stock due to fishing 
activities and was shown to affect population dynamic for both stocks (Durant \& Hjermann, 2017; Rouyer et al., 2011).

The sea temperature (ST) for the Barents Sea from 1921 until 2015 was obtained from the Kola meridian transect $\left(33^{\circ} 30^{\prime} \mathrm{E}\right.$, $70^{\circ} 30^{\prime}-72^{\circ} 30^{\prime} \mathrm{N}$ ) collected by the Polar branch of the Russian Federal Institute of Fisheries and Oceanography (PB VNIRO formerly PINRO; (Tereschenko, 1996; http://www.pinro.ru/)). The Kola meridian transect intersecting the Murman Current in the southcentral Barents Sea, covers the inflow of Atlantic and Coastal water masses from the Norwegian Sea to the south-eastern Barents Sea. This time series of temperature is representative of the Atlantic water masses in the south-central Barents Sea (Ingvaldsen et al., 2003) and correlates positively with strong year-classes of NEA cod (reviewed by Ottersen et al., 2014) and herring recruitment (Fiksen \& Slotte, 2002). The annual values made available to us were calculated by averaging temperature horizontally along the transect (5 stations) and vertically from 0 to $200 \mathrm{~m}$ water depth ( $1 \mathrm{~m}, 10 \mathrm{~m}$, 20 m, 30 m, 50 m, 75 m, 100 m, 150 m, and 200 m) (Bochkov, 1982; Tereschenko, 1996).

The station-based winter index for the North Atlantic Oscillation (wNAO) calculated for the months of December, January, February, and March for the period 1921-2015 (http://www.cgd.ucar.edu/cas/ jhurrell/indices.html, Hurrell \& Deser, 2009).

\section{4 | Statistical analysis}

Population structure, fishing, climate, and predation/competition effects on population change were investigated for both stocks for the two periods delimited by a population collapse (see collapse periods and Rouyer et al., 2011). In addition, we used environmental variables (i.e., wNAO and ST) that may influence several demographic variables simultaneously, including recruitment and age of maturity (Rouyer et al., 2011). The analysis was conducted using Generalized Additive Models (GAM), via the mgcv library in R 3.4.1 (R Core Team, 2014; Wood, 2006). GAM is a modeling technique which can be thought of as a generalization of ordinary multiple regression, where there may be both linear and nonlinear (smooth) effects of each explanatory variable (Wood, 2006). The GAM procedure automatically selects the degree of smoothing based on the Generalized Cross Validation (GCV) score. GCV is a proxy for the model's predictive performance. However, to avoid spurious and ecologically implausible relationships, we constrained the model to contain at maximum quadratic relationships, that is, we set the maximum degrees of freedom to 2 for each smooth term (i.e., $k=3$ in the GAM formulation). We wanted a parsimonious model which described the response well but was as simple as possible. We used thin plate regression splines as smoothers.

All models started with a similar formulation:

$$
\ln \left(\lambda_{1 t}\right)=s_{1}\left(\mathrm{MA}_{t}\right)+s_{2}\left(F_{t}\right)+s_{3}\left(\mathrm{ST}_{t}\right)+s_{4}\left(\mathrm{wNAO}_{t}\right)+s_{5}\left(B_{t}\right)+\varepsilon_{t}
$$

with $\lambda_{t}$ the dominant eigenvalue of the transition matrix $A_{t}, M A_{t}$ the mean age of the spawning stock at time $t, F_{t}$ the fishing mortality at time $t, \mathrm{ST}_{t}$ the Kola section sea temperature at time $t, \mathrm{wNAO}_{t}$ the winter index for the North Atlantic Oscillation between $t$ and $t+1, B_{t}$ the biomass of the cod spawning stock $\left(B_{\text {codt }}\right)$ at time $t$ for the herring models or of the juvenile herring $\left(B_{\text {herrt }}\right)$ at time $t$ for the $\operatorname{cod}$ models, and $\varepsilon_{t}$ an error term. The spline function is given as $s_{i}(\cdot)$.

\section{5 | Model selection}

We entered all candidate explanatory variables in the GAM model and conducted model selection using shrinkage. In the shrinkage approach to model selection, the smoother is modified so it allows insignificant variables to be shrunk to zero (i.e., effectively removed) as part of the smoothness selection (Wood, 2006). Thus, a reasonably optimal model is selected in a single step (i.e., all smoothers with 0 amount of smoothing are dropped simultaneously from the model). Before performing the model selection, we calculated the variance inflation factors (VIFs) between all explanatory variables to detect collinearity. Covariates with the highest VIFs were subsequently removed from the model until the highest VIF value was $<3$ (Zuur et al., 2007).

For one model (model for cod before the collapse), we found a temporal autocorrelation in the residuals of one-year lag (using autocorrelation function acf in R). For the other three models, we did not detect any significant autocorrelation. To account for the autocorrelation in the residuals of the cod model before the collapse, we used an AR(1) model (autocorrelation term or first order, in our case $\left.\ln \left(\lambda_{1 t-1}\right)\right)$.

The quantification of an individual explanatory variable's contribution to a multiple regression model explaining the variation of the stock biomass was calculated using the package relaimpo (Grömping, 2006) using the "proportional marginal variance decomposition" (pmvd) (Feldman, 2005).

\section{3 | RESULTS}

Time series of the dominant eigenvalue $\lambda_{1}$ of the transition matrix for the NSS herring (Clupea harengus) and the NEA cod (Gadus morhua) are shown in the Figure 2 and Table S1.

The best stock-specific GAM models of the dominant eigenvalue $\ln \left(\lambda_{1}\right)$ are displayed on the Figure 2 . The best GAM models of the dominant eigenvalue $\ln \left(\lambda_{1}\right)$ for the NSS herring and the NEA cod before the collapse give us an insight of the change in interaction with other species and effects of environment and harvesting (Figure 3). To check the strength of dependency of $\ln \left(\lambda_{1}\right)$ on fishing mortality $(F)$ and the validity of our modeling approach we have run the four GAM models without including $s_{2}\left(F_{t}\right)$. These four new models displayed similar effects (direction and strength) of the explanatory variables $\mathrm{MA}_{t}, \mathrm{ST}_{t}, \mathrm{WNAO}_{t}$, and $\mathrm{B}_{t}$ than the full models (see 

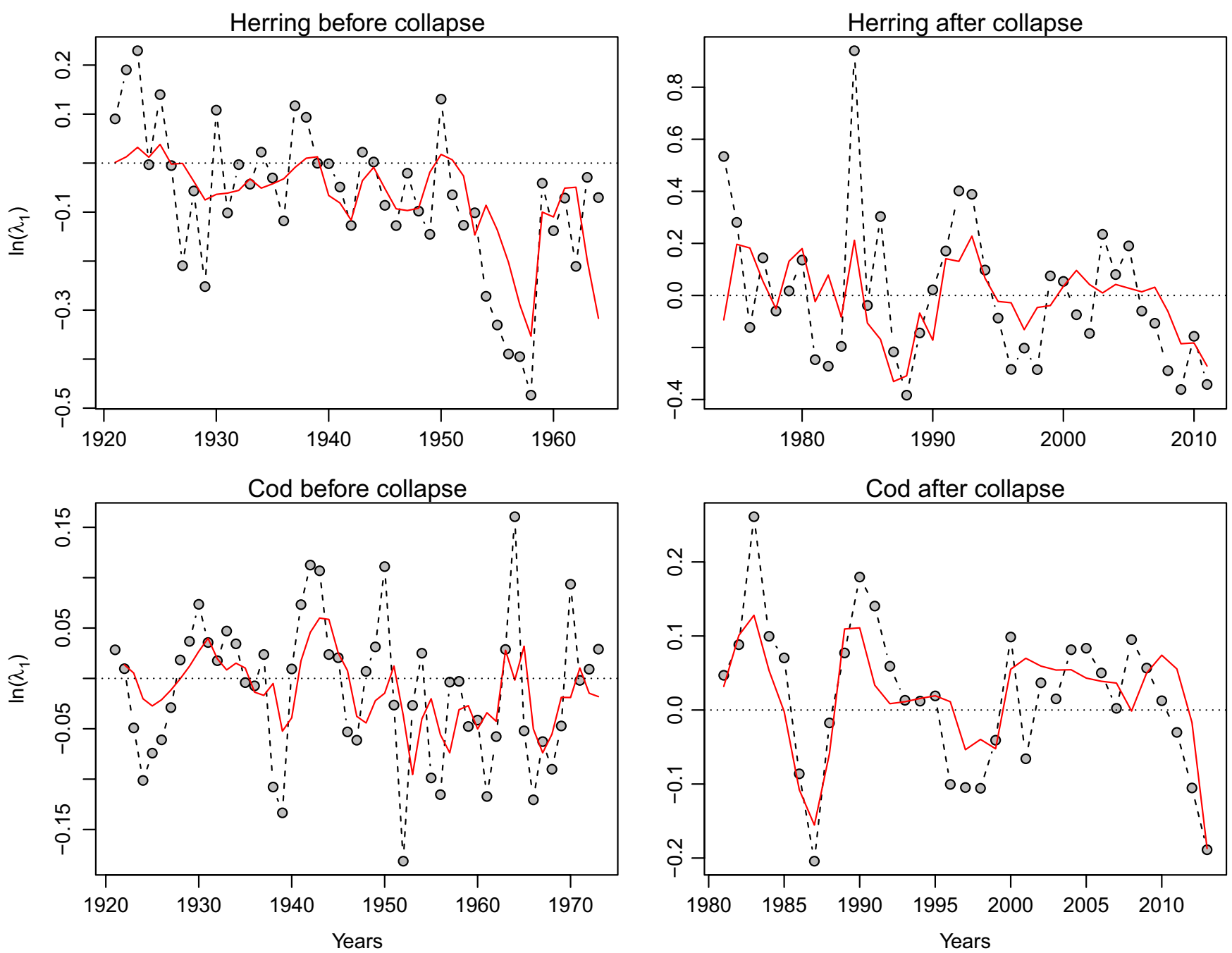

FIGURE 2 Model of the dominant eigenvalue $\lambda_{1}$ for the periods before and after the collapse for Norwegian spring spawning (NSS) herring Clupea harengus and the Northeast Arctic (NEA) cod Gadus morhua. For each stock and each period is displayed the data used to obtain the model (points) and the corresponding GAM prediction (red line)

Figure S2). This indicates that their effect on $\ln \left(\lambda_{1}\right)$ was independent of the effect of $F$.

\section{1 | Norwegian spring spawning herring models}

Before the collapse (Figure 3 first row), three explanatory variables are retained in the final model (Deviance (Dev) $=44.5 \%$ ). The cod SSB $\left(B_{\text {cod }}\right)$ shows a positive effect $(p<.001)$, mean age of the spawning stock (MA) a positive but not significant effect ( $p=.08$ ), and Kola sea temperature (ST) a positive but not significant effect $(p=.08)$ on the herring $\ln \left(\lambda_{1}\right)$. The positive effect of $B_{\text {cod }}$ may indicate a covariation.

After the collapse (Figure 3 second row), four explanatory variables are retained in the final model ( $\mathrm{Dev}=34.7 \%$ ). $B_{\text {cod }}$ shows a negative but not significant effect $(p=.11)$, MA a positive but not significant $(p=.11)$, fishing mortality $(F)$ a negative effect $(p<.01)$ and ST a positive but not significant $(p=.14)$ on the herring $\ln \left(\lambda_{1}\right)$.

\subsection{Northeast Arctic cod models}

Before the collapse (Figure 3 third row), two explanatory variables are retained in the final model ( $\mathrm{Dev}=26.5 \%$ ). $\mathrm{MA}$ and $F$ show a positive but not significant effect ( $p=.26$ and $p=.06$, respectively) on the $\operatorname{cod} \ln \left(\lambda_{1}\right)$.

After the collapse (Figure 3 fourth row), four explanatory variables are retained in the final model ( $\mathrm{Dev}=61.5 \%$ ). The juvenile herring biomass $\left(B_{\text {herr }}\right)$ shows a negative effect $(p<.01)$, MA a positive then a negative effect after $M A=6.7$ years $(p<.01)$, $\mathrm{F}$ a not significant effect ( $p=.08$ ), and ST a not significant positive effect ( $p=.13$ ) on the $\operatorname{cod} \ln \left(\lambda_{1}\right)$.

The relative importance of regressors for each model in percentage is given in Figure 4. For the herring models, the variable explaining the most variation in $\ln \left(\lambda_{1}\right)$ before the collapse is the cod SSB $\left(B_{\text {cod }}\right)$ replaced after the collapse by the fishing mortality $(F)$. For the cod models, the variable explaining the most variation before the collapse is the fishing mortality $(F)$ 

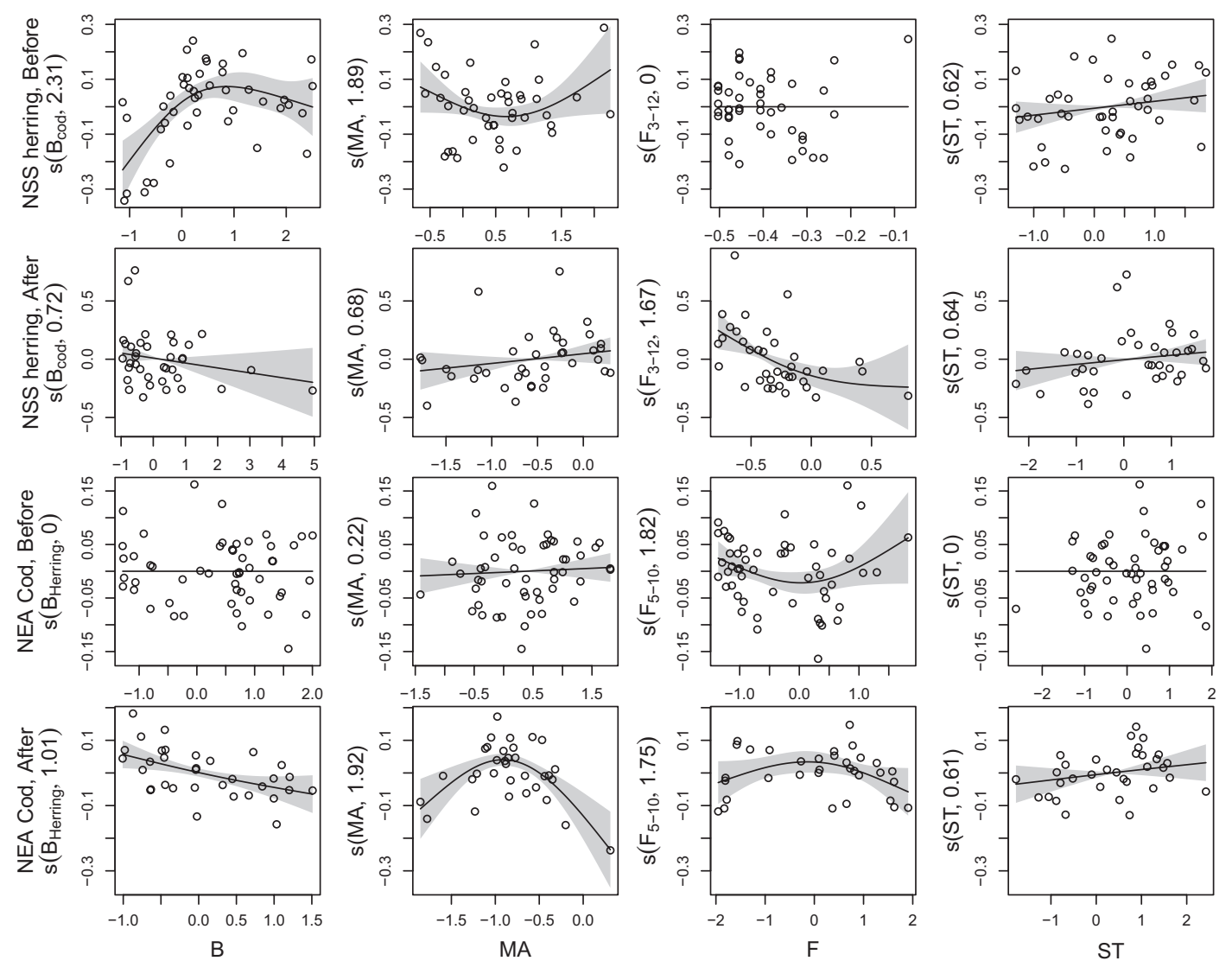

FIGURE 3 Model of the dominant eigenvalue $\lambda_{1}$ of the annual transient matrices for the Norwegian spring spawning (NSS) herring Clupea harengus and the Northeast Arctic (NEA) cod Gadus morhua before and after a population collapse. The generalized additive models (GAM) are presented for each population. For each plot, the $x$-axes show the covariate and the $y$-axes the partial effect that each covariate has on the response variable. $s(X, y)$ is the smoothing term, where $X$ represents the explanatory variable and $y$ is the estimated degrees of freedom (edf) of the smoothing term. Black line: smooth term effect of the considered covariate on the population growth with the pointwise $95 \%$ confidence interval around the mean prediction (shaded area). (s) Partial residuals calculated by adding the effect of the concerned covariate to the residuals; the model prediction at any given point is given by the sum of all partial effects plus a constant. B: cod spawning stock biomass (SSB) for the herring models and juvenile herring biomass for the cod models; MA: mean age of the spawning stock in years; F: fishing mortality; wNAO: winter North Atlantic Oscillation; ST: sea temperature at 0 to $200 \mathrm{~m}$. B, MA, F, and ST were centered to 0 and normalized

replaced after the collapse by the mean age of the spawning stock (MA).

\section{4 | DISCUSSION}

Climate forcing (Drinkwater et al., 2010) and overexploitation of resources (Brander et al., 2010) have both been identified as the dominant factors affecting biodiversity and abundance of marine species. Since the beginning of the 20th century, several fish stocks and associated fisheries have collapsed (Branch et al., 2011; Hilborn, 2007). While environmental effects are generally stronger on younger stages, fishing primarily affects larger and older individuals. The combination of the two results in an increased variability in abundance and a greater risk of collapse (Sguotti et al., 2019). In addition, exploitation may alter population characteristics in such a way that the nature of response to environmental variability in a population will change (Planque et al., 2010; Rouyer et al., 2011). In other words, there are multiple feedback loops that might interact with each other potentially leading to stock collapses (Bakun \& Weeks, 2006) with effects on the ecosystem that are still not completely understood.

By comparing the effect of different variables on $\ln \left(\lambda_{1}\right)$ (a proxy of the changes occurring in the population between the two years), before and after a population collapse, in NSS herring (Clupea harengus) and NEA cod (Gadus morhua), we were able to explore the effect of such collapse on the population dynamics. There is no long time continuous and consistent time series survey data readily available that could be used to compare the dynamics before or after the collapse for these stocks (particularly before the collapses). Our study then relies on outputs from four virtual population analysis (VPA) models (Shepherd \& Pope, 2002); a cohort modeling technique commonly used in fisheries science for stock assessment and reconstruction of historical fish numbers. VPAs are based on different sources of information (fisheries catch and scientific survey) and take into account the sampling intensity thus, while imperfect, give one of the best available estimate of historical 


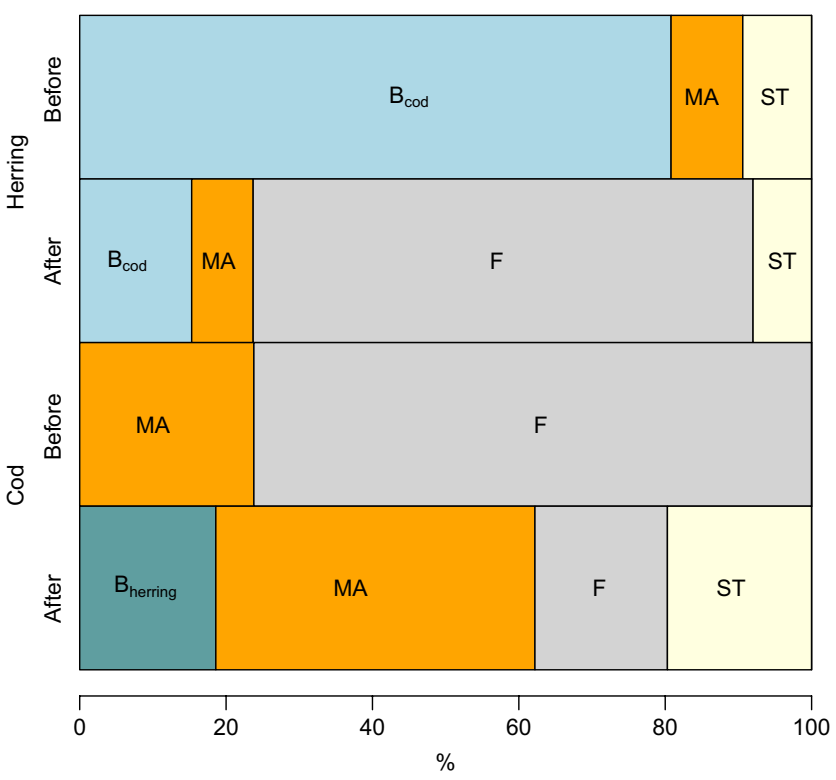

FIGURE 4 Relative importance of regressors (using proportional marginal variance decomposition, see methods) for each model in percent before and after a population collapse for herring and cod. $B$ : cod SSB for the herring models or juvenile herring biomass for the cod models; MA: mean age of the spawning stock; F: fishing mortality; ST: sea temperature at 0 to 200 m; wNAO: winter North Atlantic Oscillation

population structure and numbers. However, each VPA has its particularities linked to data quality and specific methods. To reduce the potential impact of such issues, we calculated annual transition matrices independently for each VPA time series thus giving comparable time series of population dynamical properties before and after the collapse (see Table S1).

Previous studies have demonstrated that the realized population growth rate may be sensitive to change in the population structure linked, for example, to overfishing (Rouyer et al., 2011) associated with changing effects of sea temperature and fishing mortality on elasticity to recruitment (Durant \& Hjermann, 2017). In this study, we extend these results by looking at the effect of a major decline in abundance on species interactions. Our results indicate that a population collapse in addition to an altered response to abiotic environmental variations (Rouyer et al., 2011) may lead to altered trophic interactions with subsequent potential effects at the ecosystem level. In other words, while the stocks have regained the abundance from before the collapse, the system is potentially quite different (Figure 4).

The explanatory power of our models is ranging from 26.5 to $61.5 \%$ (as expressed by the deviance) indicating that they are reasonably good for the type of analyze conducted (Figure 2). A reason for this somewhat low explanatory power could be the relatively high level of noise in the data, in particular for the herring before the collapse. For instance, a major part of the fishery before 1977 targeted immature herring (0-2 years old, Toresen \& Østvedt, 2000) that may have altered the size composition of the stock. Another reason could be that we were unable to account for important explanatory variables. For example, it would have been useful to include the capelin Mallotus villosus abundance in our analysis, a key species in the Barents Sea (Hjermann et al., 2007). Unfortunately, capelin data are available only from 1974 and the comparison of its effect before/ after the collapse is not possible. We can speculate that, following the absence of negative effect of herring abundance on cod before the cod collapse, the link herring-capelin-cod was potentially not as strong as it is currently (Hjermann et al., 2007). Since 1984, the NEA cod diet (fish sized $20-90 \mathrm{~cm}$ ) is composed on average of only about 3\% of herring and about 33\% of capelin (Holt et al., 2019). Conversely, recent works on historical stomach's contents of NEA cod in the Barents Sea indicate that before the collapse, the herring was much more abundant than capelin in the cod diet (Townhill et al., 2015, 2021). Such diet difference is another indication of the change of the link herring-capelin-cod after the collapses. However, the absence of positive effect of herring on cod before the collapse may indicate that the juvenile herring was not a main prey for cod in the Barents Sea either despite a relatively high occurrence of herring in cod diet in the 1930s (see Figure S3 for herring abundance in the cod diet over the years) (Durant et al., 2014; Holt et al., 2019). This is confirmed by the positive effect of cod abundance on herring $\ln \left(\lambda_{1}\right)$ before the collapse indicating a covariation. The absence of a negative effect of cod on herring before the collapse may also be explained by the very high abundance of herring relatively to the cod. However, note that the covariation was reduced at high cod abundance (Figure 3). Since the abundance of both herring and cod increased at the same time, explaining the observed covariation, the predation of cod on herring may not have been strong enough to be captured by the statistical analysis. On the reverse, after the collapse, the biomass of cod relatively to the abundance of herring was nearly quadrupled due to some years with very low herring abundance and recent years with very high cod biomass (Table S1).

Atlantic cod is considered a major predator of herring (Hamre, 1988, 1994; Link et al., 2009), particularly for the juvenile stage (de Barros \& Toresen, 1998; Johansen et al., 2004), and we thus expected to observe a negative effect on herring population. However, we only observed, albeit not significantly, a negative effect of cod on herring after the herring collapse. In addition, a recent work shows a relatively little predation of cod on herring in the Barents Sea (Holt et al., 2019) which fit with an expected predation pressure relief after the cod stock collapses (e.g., for Gulf of Maine-Georges Bank Atlantic herring; Overholtz \& Link, 2007). Furthermore, the change of cod diet toward a higher capelin diet after the 70s (Townhill et al., 2015,2021 ) may also have led to a predation pressure relief.

On the other hand, the herring is also a major predator of capelin larvae in the Barents Sea (Hallfredsson \& Pedersen, 2009; Hjermann et al., 2010). In periods of good herring recruitment, the recruitment of capelin population in the Barents Sea, a main prey item for cod (ICES, 2012; Johansen et al., 2004; Mehl, 1989), is strongly reduced due to herring predation on capelin larvae (Hamre, 1994). In the recent years, cod population growth was found to be positively related to the abundance of capelin (Durant et al., 2008). An increase of the herring predation on capelin would explain the 
negative effect of herring on the cod population (Figure 3) as would an increase of herring predation on cod eggs (Akimova et al., 2019; Segers et al., 2007). Alternatively, herring larvae being less sensitive to food depletion than cod larvae (Folkvord et al., 2009) they may outcompete cod larvae for food in years of high herring abundance (Hjermann et al., 2013) since their larvae are drifting along a similar route toward the Barents Sea (Vikebø et al., 2011). In the Georges Bank, predation by herring on cod early life stages was shown to delay the population rebuilding (Collie et al., 2013). Similar results have also been reported for interactions between cod and herring in the North Sea (Essington et al., 2014; Fauchald, 2010). However, this mechanism may not have prevented NEA cod rebuilding after its collapse (1974 onward) since the NSS herring stock was at this time still low in abundance as a result of the herring collapse in the late 1960s. During the same period, food in the Barents Sea, that is capelin stock, was also highly abundant (Durant \& Hjermann, 2017). Conditions may have thus been favorable for a relaxed competition among surviving NEA cod, leading to an increase in food intake and hence increased somatic growth and reproduction (Van Leeuwen et al., 2008).

Many marine ecosystems are increasingly susceptible to sudden nonlinear transformations due to climate warming (Hoegh-Guldberg \& Bruno, 2010). Nonadditive effect of the environment (i.e., climate) on population dynamics has been observed in both terrestrial (Stenseth et al., 2004, 2015) and marine systems (Ciannelli et al., 2013; Dingsør et al., 2007) and may lead to different population equilibrium (Durant et al., 2020). This is particularly true for the Atlantic cod (Fauchald et al., 2011; Frank et al., 2011; Scheffer et al., 2001; Sguotti et al., 2019; Vasilakopoulos \& Marshall, 2015). Using mass-balance models, Bundy (2005) have shown that the fishinginduced collapse of the cod stock led to a change in the structure of the eastern Scotian Shelf ecosystem (see also Bundy et al., 2009). However, the predator structure in Barents Sea system did not change as the cod remaining the main predator after the collapse, its stock having recovered.

In their study on cod and herring, Rouyer et al. (2011) considered the change in the realized population growth as a continuous variable and explored over time the effect of the population structure, fishing intensity, and sea temperature changes on its variation. In our study, we explored the change occurring to the population before and after a major decline in abundance considering the periods independently of each other (i.e., nonlinear) and looked at the difference in the resulting species interaction. We found that the collapse of the population may have led to more structural change in the ecosystem than expected, as the species interaction has changed. Similar to Rouyer et al. (2011), we found that the cod stock is more sensitive to climate variation in the recent period compared to before the population collapse (Figure 3). However, note that the period after the collapse corresponds mostly to a period of sea temperature increase with strong effect on the Barents Sea structure (Fossheim et al., 2015). Part of the observed differences (e.g., increased sensitivity to climate variation, Figure 3) could be explained by climate warming and by the change in feeding opportunities.
Keeping in mind that our models have a different formulation, our results for herring differ from Rouyer et al. (2011) as we found that the fishing mortality is affecting the population dynamic after the collapse and not before.

Marine ecosystems are subjected to a range of exploitation intensities that can lead to stock declines and even collapses (Worm et al., 2009). While management actions have achieved measurable effects by reduction of the exploitation rates (Dragesund et al., 2008; Ulltang, 1987), these actions are not always resulting in a stock regeneration (Collie et al., 2013; Hutchings \& Rangeley, 2011) or ecosystem regeneration, new ecological baseline may have developed (e.g., Blenckner et al., 2015). Indeed, changes of population structure linked to overexploitation have been shown to affect how a population responds to climate and exploitation forcing (Brosset et al., 2019; Durant \& Hjermann, 2017; Hidalgo, Rouyer, et al., 2012; Rouyer et al., 2011). In this study, we show that in addition, the occurrence of a collapse is creating a nonlinearity in the species interactions that may eventually impact the functioning of the food chain similar to what was observed for the effect of climate warming (Ciannelli et al., 2013; Dingsør et al., 2007; Durant et al., 2020).

\section{ACKNOWLEDGMENTS}

The Research Council of Norway supported this work through the projects: SUSTAIN (244647/E10), SPACESHIFT (280468) and FISHCOM (280467).

\section{CONFLICT OF INTEREST}

The authors have no conflicts of interest to report.

\section{AUTHOR CONTRIBUTIONS}

Joël M. Durant: Conceptualization (lead); data curation (lead); formal analysis (lead); funding acquisition (equal); investigation (lead); methodology (lead); project administration (equal); validation (lead); visualization (lead); writing-original draft (lead). Leana Aarvold: Formal analysis (supporting); investigation (supporting); methodology (supporting); validation (supporting); visualization (supporting); writingoriginal draft (supporting). Øystein Langangen: Conceptualization (supporting); formal analysis (supporting); funding acquisition (equal); investigation (supporting); methodology (supporting); project administration (equal); writing-original draft (supporting).

\section{DATA AVAILABILITY STATEMENT}

Source and accessibility of the data used in this study are given in Table 1 and Table S1. wNAO at https://climatedataguide.ucar.edu/ climate-data/hurrell-north-atlantic-oscillation-nao-index-stationbased. Fish abundance data at http://www.ices.dk/community/ groups/Pages/AFWG.aspx and see Table 1. Kola sea temperature at http://www.pinro.ru/labs/hid/kolsec22.php.

\section{ORCID}

Joël M. Durant (iD https://orcid.org/0000-0002-1129-525X

Øystein Langangen (iD https://orcid.org/0000-0002-6977-6128 


\section{REFERENCES}

Akimova, A., Hufnagl, M., \& Peck, M. A. (2019). Spatiotemporal dynamics of predators and survival of marine fish early life stages: Atlantic cod (Gadus morhua) in the North Sea. Progress in Oceanography, 176, 102121. https://doi.org/10.1016/j. pocean.2019.102121

Bakketeig, I. E., Hauge, M., Kvamme, C., Sunnset, B. H., \& Toft, K. Ø. (2016). Havforskningsrapporten 2016. Fisken Og Havet, 1, 99.

Bakun, A., \& Weeks, S. J. (2006). Adverse feedback sequences in exploited marine systems: Are deliberate interruptive actions warranted? Fish and Fisheries, 7, 316-333. https://doi.org/10.1111/ j.1467-2979.2006.00229.x

Beisner, B. E., Haydon, D. T., \& Cuddington, K. (2003). Alternative stable states in ecology. Frontiers in Ecology and the Environment, 1, 376-382. https://doi.org/10.1890/1540-9295(2003)001[0376: ASSIE]2.0.CO;2

Bengtsson, L., Semenov, V. A., \& Johannessen, O. M. (2004). The early twentieth-century warming in the arctic-A possible mechanism. Journal of Climate, 17, 4045-4057.

Benson, A. J., \& Trites, A. W. (2002). Ecological effects of regime shifts in the Bering Sea and eastern North Pacific Ocean. Fish and Fisheries, 3, 95-113.

Blenckner, T., Llope, M., Mollmann, C., Voss, R., Quaas, M. F., Casini, M., Lindegren, M., Folke, C., \& Stenseth, N. C. (2015). Climate and fishing steer ecosystem regeneration to uncertain economic futures. Proceedings of the Royal Society B-Biological Sciences, 282, 20142809. https://doi.org/10.1098/rspb. 2014.2809

Bochkov, Y. A. (1982). Water temperature in 0-200 m layer in the KolaMeridian section in the Barents Sea, 1900-1981. Trudy PINRO, Murmansk, 46, 113-122. (in Russian).

Branch, T. A., Jensen, O. P., Ricard, D., Ye, Y., \& Hilborn, R. A. Y. (2011). Contrasting global trends in marine fishery status obtained from catches and from stock assessments. Conservation Biology, 25(4), 777-786. https://doi org/10.1111/j.1523-1739.2011.01687.x

Brander, K., Botsford, L. W., Ciannelli, L., Fogarty, M. J., Heath, M. Planque, B., Shannon, L., \& Wieland, K. (2010). Human impacts on marine ecosystems. In M. Barange, J. G. Field, R. P. Harris, E. E. Hofmann, R. I. Perry, \& F. Werner (Eds.), Marine ecosystems and global change. Oxford University Press.

Brosset, P., Durant, J. M., van Beveren, E., \& Plourde, S. (2019). Fish population growth in the Gulf of St Lawrence: Effects of climate, fishing and predator abundance. Marine Ecology Progress Series, 624, 167181. https://doi.org/10.3354/meps13029

Bundy, A. (2005). Structure and functioning of the eastern Scotian Shelf ecosystem before and after the collapse of groundfish stocks in the early 1990s. Canadian Journal of Fisheries and Aquatic Sciences, 62, 1453-1473.

Bundy, A., Heymans, J. J., Morissette, L., \& Savenkoff, C. (2009). Seals, cod and forage fish: A comparative exploration of variations in the theme of stock collapse and ecosystem change in four Northwest Atlantic ecosystems. Progress in Oceanography, 81, 188-206. https://doi.org/10.1016/j.pocean.2009.04.010

Ciannelli, L., Fisher, J. A. D., Skern-Mauritzen, M., Hunsicker, M. E., Hidalgo, M., Frank, K. T., \& Bailey, K. M. (2013). Theory, consequences and evidence of eroding population spatial structure in harvested marine fishes: A review. Marine Ecology Progress Series, 480, 227-243. https://doi.org/10.3354/meps10067

Collie, J., Minto, C., Worm, B., \& Bell, R. (2013). Predation on prerecruits can delay rebuilding of depleted cod stocks. Bulletin of Marine Science, 89, 107-122.

Daskalov, G. M. (2002). Overfishing drives a trophic cascade in the Black Sea. Marine Ecology Progress Series, 225, 53-63. https://doi. org/10.3354/meps225053 de Barros, P., \& Toresen, R. (1998). Variable natural mortality rate of juvenile Norwegian spring-spawning herring (Clupea harengus L.) in the Barents Sea. ICES Journal of Marine Science, 55, 430-442.

de Kroon, H., Plaisier, A., van Groenendael, J., \& Caswell, H. (1986). Elasticity: The relative contribution of demographic parameters to population growth rate. Ecology, 67, 1427-1431. https://doi. org/10.2307/1938700.

Dingsør, G. E., Ciannelli, L., Chan, K. S., Ottersen, G., \& Stenseth, N. C. (2007). Density dependence and density independence during the early life stages of four marine fish stocks. Ecology, 88, 625-634.

Dragesund, O., Østvedt, O. J., \& Toresen, R. (2008). Norwegian springspawning herring: History of fisheries, biology and stock assessment. In O. Nakken (Ed.), Norwegian spring-spawning herring and Northeast Arctic cod: 100 years of research and management. Tapir Academic Press.

Drinkwater, K., Hunt, G. L., Lehodey, P., Lluch-Cota, S., Murphy, E. J., Sakurai, Y., Schwing, F., Beaugrand, G., \& Svein, S. (2010). Climate forcing on marine ecosystems. In: M. Barange, J. G. Field, R. P. Harris, E. E. Hofmann, R. I. Perry, \& F. Werner (Eds.), Marine ecosystems and global change. Oxford University Press.

Durant, J. M., \& Hjermann, D. Ø. (2017). Age-structure, harvesting and climate effects on population growth of Arcto-boreal fish stocks. Marine Ecology Progress Series, 577, 177-188. https://doi. org/10.3354/meps12210

Durant, J. M., Hjermann, D. Ø., Sabarros, P. S., \& Stenseth, N. C. (2008). Northeast arctic cod population persistence in the Lofoten-Barents Sea system under fishing. Ecological Applications, 18, 662-669. https://doi.org/10.1890/07-0960.1

Durant, J. M., Ono, K., Stenseth, N. C., \& Langangen, Ø. (2020). Nonlinearity in interspecific interactions in response to climate change: Cod and haddock as an example. Global Change Biology, 26, 55545563. https://doi.org/10.1111/gcb.15264

Durant, J. M., Skern-Mauritzen, M., Krasnov, Y. V., Nikolaeva, N. G. Lindstrom, U., \& Dolgov, A. (2014). Temporal dynamics of top predators interactions in the Barents Sea. PLoS One, 9(11), e110933. https://doi.org/10.1371/journal.pone.0110933

Engelhard, G. H., \& Heino, M. (2004). Maturity changes in Norwegian spring-spawning herring before, during, and after a major population collapse. Fisheries Research, 66, 299-310.

Essington, T. E., Baskett, M. L., Sanchirico, J. N., \& Walters, C. (2014). A novel model of predator-prey interactions reveals the sensitivity of forage fish: Piscivore fishery trade-offs to ecological conditions. ICES Journal of Marine Science, 72, 1349-1358.

Fauchald, P. (2010). Predator-prey reversal: A possible mechanism for ecosystem hysteresis in the North Sea? Ecology, 91, 2191-2197. https://doi.org/10.1890/09-1500.1

Fauchald, P., Skov, H., Skern-Mauritzen, M., Hausner, V. H., Johns, D., \& Tveraa, T. (2011). Scale-dependent response diversity of seabirds to prey in the North Sea. Ecology, 92, 228-239.

Feldman, B. E. (2005). Relative importance and value. SSRN Electronic Journal. https://doi.org/10.2139/ssrn.2255827

Fiksen, Ø., \& Slotte, A. (2002). Stock-environment recruitment models for Norwegian spring spawning herring (Clupea harengus). Canadian Journal of Fisheries and Aquatic Sciences, 59, 211-217.

Folkvord, A., Fiksen, O., Høie, H., Johannessen, A., Otterlei, E., \& Vollset, K. W. (2009). What can size distributions within cohorts tell us about ecological processes in fish larvae? Scientia Marina, 73S1, 119-130.

Fossheim, M., Primicerio, R., Johannesen, E., Ingvaldsen, R. B., Aschan, M. M., \& Dolgov, A. V. (2015). Recent warming leads to a rapid borealization of fish communities in the Arctic. Nature Climate Change, 5, 673-677.

Frank, K. T., Petrie, B., Fisher, J. A. D., \& Leggett, W. C. (2011). Transient dynamics of an altered large marine ecosystem. Nature, 477, 86-89. 
Grömping, U. (2006). Relative importance for linear regression in R: The package relaimpo. Journal of Statistical Software, 17, 1-27.

Hallett, T. B., Coulson, T., Pilkington, J. G., Clutton-Brock, T. H., Pemberton, J. M., \& Grenfell, B. T. (2004). Why large-scale climate indices seem to predict ecological processes better than local weather. Nature, 430, 71-75.

Hallfredsson, E. H., \& Pedersen, T. (2009). Effects of predation from juvenile herring (Clupea harengus) on mortality rates of capelin (Mallotus villosus) larvae. Canadian Journal of Fisheries and Aquatic Sciences, 66, 1693-1706.

Hamre, J. (1988). Some aspects of the interrelation between the herring in the Norwegian Sea and the stocks of capelin and cod in the Barents Sea. ICES CM 1988/H:42, 1-15.

Hamre, J. (1994). Biodiversity and exploitation of the main fish stocks in the Norwegian-Barents Sea ecosystem. Biodiversity and Conservation, 3, 473-492. https://doi.org/10.1007/BF00115154

Hare, S. R., \& Mantua, N. J. (2000). Empirical evidence for North Pacific regime shifts in 1977 and 1989. Progress in Oceanography, 47, 103-145.

Hidalgo, M., Gusdal, Y., Dingsor, G. E., Hjermann, D. Ø., Ottersen, G., Stige, L. C., Melsom, A., \& Stenseth, N. C. (2012). A combination of hydrodynamical and statistical modelling reveals non-stationary climate effects on fish larvae distributions. Proceedings of the Royal Society B-Biological Sciences, 279(1727), 275-283. https://doi. org/10.1098/rspb.2011.0750

Hidalgo, M., Rouyer, T., Bartolino, V., Cervino, S., Ciannelli, L., Massuti, E., Jadaud, A., Saborido-Rey, F., Durant, J. M., Santurtun, M., Pineiro, C., \& Stenseth, N. C. (2012). Context-dependent interplays between truncated demographies and climate variation shape the population growth rate of a harvested species. Ecography, 35(7), 637-649. https://doi.org/10.1111/j.1600-0587.2011.07314.x

Hilborn, R. A. Y. (2007). Reinterpreting the state of fisheries and their management. Ecosystems, 10, 1362-1369. https://doi.org/10.1007/ s10021-007-9100-5

Hjermann, D. Ø., Bogstad, B., Dingsør, G. E., Gjøsæter, H., Ottersen, G., Eikeset, A. M., \& Stenseth, N. C. (2010). Trophic interactions affecting a key ecosystem component: A multi-stage analysis of the recruitment of the Barents Sea capelin. Canadian Journal of Fisheries and Aquatic Sciences, 67, 1363-1375.

Hjermann, D. Ø., Bogstad, B., Eikeset, A. M., Ottersen, G., Gjosaeter, H., \& Stenseth, N. C. (2007). Food web dynamics affect Northeast Arctic cod recruitment. Proceedings of the Royal Society B-Biological Sciences, 274, 661-669.

Hjermann, D., Fisher, J. A. D., Rouyer, T., Frank, K. T., \& Stenseth, N. C. (2013). Spatial analysis of North Sea cod recruitment: Concurrent effects of changes in spawning stock biomass, temperature and herring abundance. Marine Ecology Progress Series, 480, 263-275. https://doi.org/10.3354/meps10315

Hjermann, D. Ø., Stenseth, N. C., \& Ottersen, G. (2004). The population dynamics of Northeast Arctic cod (Gadus morhua) through two decades: an analysis based on survey data. Canadian Journal of Fisheries and Aquatic Sciences, 61, 1747-1755.

Hoegh-Guldberg, O., \& Bruno, J. F. (2010). The impact of climate change on the World's Marine Ecosystems. Science, 328, 1523-1528.

Holt, R. E., Bogstad, B., Durant, J. M., Dolgov, A. V., \& Ottersen, G. (2019). Barents Sea cod (Gadus morhua) diet composition: Longterm interannual, seasonal, and ontogenetic patterns. ICES Journal of Marine Science, 76(6), 1641-1652. https://doi.org/10.1093/ icesjms/fsz082

Hurrell, J. W., \& Deser, C. (2009). North Atlantic climate variability: The role of the North Atlantic Oscillation. Journal of Marine Systems, 78, 28-41.

Hutchings, J. A., \& Rangeley, R. W. (2011). Correlates of recovery for Canadian Atlantic cod (Gadus morhua). Canadian Journal of Zoology, $89,386-400$.
Hylen, A. (2002). Fluctuations in abundance of Northeast Arctic cod during the 20th century. ICES Marine Science Symposia, 215, 543550. https://doi.org/10.1046/j.1467-2979.2003.00112.x

ICES. (2007). Report of the working group on Northern pelagic and blue whiting fisheries (WGNPBW), 27 August-1 September 2007, Vigo, Spain. ICES. CM 2007/ACFM, 29, pp. 229.

ICES. (2012). Report of the Arctic Fisheries Working Group 2012 (AFWG), 20 - 26 April 2012, ICES Headquarters, Copenhagen. ICES CM 2012/ ACOM, 05, (633 pp).

ICES. (2015). Report of the Working Group on Widely Distributed Stocks (WGWIDE), 25 August - 31 August 2015, Pasaia, Spain. ICES CM 2015/ACOM: 15, (646 pp).

ICES. (2017). Report of the Arctic Fisheries Working Group (AFWG) 19 - 25 April 2017, Copenhagen, Denmark. ICES CM 2017/ACOM, 06, (486 pp).

Ingvaldsen, R., Loeng, H., Ådlandsvik, B., \& Ottersen, G. (2003). Climate variability in the Barents Sea during the 20th century with focus on the 1990s. ICES Marine Science Symposia, 219, 160-168.

Johansen, G. O., Bogstad, B., Mehl, S., \& Ulltang, Ø. (2004). Consumption of juvenile herring (Clupea harengus) by cod (Gadus morhua) in the Barents Sea: A new approach to estimating consumption in piscivorous fish. Canadian Journal of Fisheries and Aquatic Sciences, 61, 343-359.

Law, R. (2000). Fishing, selection, and phenotypic evolution. ICES Journal of Marine Science, 57, 659-668.

Link, J. S., Bogstad, B., Sparholt, H., \& Lilly, G. R. (2009). Trophic role of Atlantic cod in the ecosystem. Fish and Fisheries, 10, 58-87.

Mehl, S. (1989). The Northeast Arctic cod stock's consumption of commercially exploited prey species in 1984-1986. Rapport Et Procesverbaux Des Réunions Du Conseil International Pour L'exploration De La Mer, 188, 185-205.

Minto, C., \& Worm, B. (2012). Interactions between small pelagic fish and young cod across the North Atlantic. Ecology, 93, 2139-2154.

Myers, R. A., \& Worm, B. (2003). Rapid worldwide depletion of predatory fish communities. Nature, 423, 280.

Ottersen, G., Bogstad, B., Yaragina, N. A., Stige, L. C., Vikebø, F. B., \& Dalpadado, P. (2014). A review of early life history dynamics of Barents Sea cod (Gadus morhua). ICES Journal of Marine Science, 71, 2064-2087.

Ottersen, G., Hjermann, D. O., \& Stenseth, N. C. (2006). Changes in spawning stock structure strengthen the link between climate and recruitment in a heavily fished cod (Gadus morhua) stock. Fisheries Oceanography, 15, 230-243. https://doi. org/10.1111/j.1365-2419.2006.00404.x

Ottersen, G., \& Loeng, H. (2000). Covariability in early growth and yearclass strength of Barents Sea cod, haddock, and herring: The environmental link. ICES Journal of Marine Science, 57(2), 339-348. https://doi.org/10.1006/jmsc.1999.0529

Ottersen, G., Stige, L. C., Durant, J. M., Chan, K. S., Rouyer, T. A., Drinkwater, K. F., \& Stenseth, N. C. (2013). Temporal shifts in recruitment dynamics of North Atlantic fish stocks: Effects of spawning stock and temperature. Marine Ecology Progress Series, 480, 205-225. https://doi.org/10.3354/meps10249

Overholtz, W. J., \& Link, J. S. (2007). Consumption impacts by marine mammals, fish, and seabirds on the Gulf of Maine-Georges Bank Atlantic herring (Clupea harengus) complex during the years 19772002. ICES Journal of Marine Science, 64, 83-96.

Planque, B., Fromentin, J.-M., Cury, P., Drinkwater, K. F., Jennings, S., Perry, R. I., \& Kifani, S. (2010). How does fishing alter marine populations and ecosystems sensitivity to climate? Journal of Marine Systems, 79, 403-417.

R Core Team (2014). R: A language and environment for statistical computing. R Foundation for Statistical Computing. Retrieved from http://www.R-project.org 
Rouyer, T., Ottersen, G., Durant, J. M., Hidalgo, M., Hjermann, D. O. Persson, J., Stige, L. C., \& Stenseth, N. C. (2011). Shifting dynamic forces in fish stock fluctuations triggered by age truncation? Global Change Biology, 17(10), 3046-3057. https://doi. org/10.1111/j.1365-2486.2011.02443.x

Scheffer, M., Carpenter, S., Foley, J. A., Folke, C., \& Walker, B. (2001) Catastrophic shifts in ecosystems. Nature, 413, 591-596.

Segers, F. H. I. D., Dickey-Collas, M., \& Rijnsdorp, A. D. (2007). Prey selection by North Sea herring (Clupea harengus), with special reference to fish eggs. ICES Journal of Marine Science, 64, 60-68.

Sguotti, C., Otto, S. A., Frelat, R., Langbehn, T. J., Plambech Ryber, M., Lindegren, M., Durant, J. M., Stenseth, N. Chr., \& Möllmann, C. (2019). Catastrophic dynamics limit Atlantic cod recovery. Proceedings of the Royal Society B: Biological Sciences, 286(1898), 20182877. https://doi.org/10.1098/rspb.2018.2877

Shepherd, J. G., \& Pope, J. G. (2002). Dynamic pool models I: Interpreting the past using virtual population analysis. In P. J. B. Hart \& J. D. Reynolds (Eds.), Handbook of fish biology and fisheries. Blackwell publishing.

Steneck, R. S., \& Wahle, R. A. (2013). American lobster dynamics in a brave new ocean. Canadian Journal of Fisheries and Aquatic Sciences, 70, 280-283.

Stenseth, N. C., Chan, K. S., Tavecchia, G., Coulson, T., Mysterud, A., Clutton-Brock, T., \& Grenfell, B. (2004). Modelling non-additive and nonlinear signals from climatic noise in ecological time series: Soay sheep as an example. Proceedings of the Royal Society B-Biological Sciences, 271, 1985-1993.

Stenseth, N. C., Durant, J. M., Fowler, M. S., Matthysen, E., Adriaensen, F., Jonzén, N., Chan, K.-S., Liu, H., de Laet, J., Sheldon, B. C., Visser, M. E., \& Dhondt, A. A. (2015). Testing for effects of climate change on competitive relationships and coexistence between two bird species. Proceedings of the Royal Society B-Biological Sciences, 282, 20141958. https://doi.org/10.1098/rspb.2014.1958

Tereschenko, V. V. (1996). Seasonal and year-to-year variations of temperature and salinity along the Kola meridian transect. ICES CM, C11, 24.

Tiedemann, M., Nash, R. D. M., Stenevik, E. K., Stiasny, M. H., Slotte, A., \& Kjesbu, O. S. (2021). Environmental influences on Norwegian spring-spawning herring (Clupea harengus L.) larvae reveal recent constraints in recruitment success. ICES Journal of Marine Science, 78(2), 640-652. https://doi.org/10.1093/icesjms/fsaa072

Toresen, R., \& Østvedt, O. J. (2000). Variation in abundance of Norwegian spring-spawning herring (Clupea harengus, Clupeidae) throughout the 20th century and the influence of climatic fluctuations. Fish and Fisheries, 1(3), 231-256. https://doi. org/10.1111/j.1467-2979.2000.00022.x
Townhill, B. L., Holt, R. E., Bogstad, B., Durant, J. M., Pinnegar, J. K., Dolgov, A. V., Yaragina, N. A., Johannesen, E., \& Ottersen, G. (2021). Diets of the Barents Sea cod (Gadus morhua) from the 1930s to 2018. Earth System Science Data, 13, 1361-1370. https://doi. org/10.5194/essd-13-1361-2021

Townhill, B. L., Maxwell, D., Engelhard, G. H., Simpson, S. D., \& Pinnegar, J. K. (2015). Historical arctic logbooks provide insights into past diets and climatic responses of cod. PLoS One, 10, e0135418.

Ulltang, Ø. (1987). Potential gains from improved management of the Northeast Arctic cod stock. Fisheries Research, 5, 243-252.

van Leeuwen, A., de Roos, A. M., \& Persson, L. (2008). How cod shapes its world. Journal of Sea Research, 60, 89-104.

Vasilakopoulos, P., \& Marshall, C. T. (2015). Resilience and tipping points of an exploited fish population over six decades. Global Change Biology, 21, 1834-1847.

Vikebø, F. B., Adlandsvik, B., Albretsen, J., Sundby, S., Stenevik, E. K., Huse, G., Svendsen, E., Kristiansen, T., \& Eriksen, E. (2011). Realtime ichthyoplankton drift in northeast arctic cod and Norwegian spring-spawning herring. PLoS One, 6.

Wood, S. N. (2006). Generalized additive models: An introduction with R. Chapman \& Hall/CRC.

Worm, B., Hilborn, R., Baum, J. K., Branch, T. A., Collie, J. S., Costello, C., Fogarty, M. J., Fulton, E. A., Hutchings, J. A., Jennings, S., Jensen, O. P., Lotze, H. K., Mace, P. M., McClanahan, T. R., Minto, C., Palumbi, S. R., Parma, A. M., Ricard, D., Rosenberg, A. A., ... Zeller, D. (2009). Rebuilding Global Fisheries. Science, 325, 578-585.

Zuur, A. F., leno, E. N., \& Smith, G. M. (2007). Analysing Ecological Data. (1-672). Springer. https://doi.org/10.1007/978-0-387-45972-1

\section{SUPPORTING INFORMATION}

Additional supporting information may be found in the online version of the article at the publisher's website.

How to cite this article: Durant, J. M., Aarvold, L., \& Langangen, Ø. (2021). Stock collapse and its effect on species interactions: Cod and herring in the Norwegian-Barents Seas system as an example. Ecology and Evolution, 00, 1-12. https://doi.org/10.1002/ece3.8336 